Published in final edited form as:

J Cancer Surviv. 2016 October ; 10(5): 850-864. doi:10.1007/s11764-016-0530-y.

\title{
Complementary and Alternative Medicine Use among US Cancer Survivors
}

\author{
Gabriella M. John, MS ${ }^{1}$, Dawn L. Hershman, MD, MS ${ }^{1,2,3}$, Laura Falci, MPH ${ }^{1}$, Zaixing Shi, \\ MS ${ }^{1}$, Wei-Yann Tsai, $\mathbf{P h D}^{4,3}$, and Heather Greenlee, ND, $\mathbf{P h D}^{1,3}$ \\ ${ }^{1}$ Department of Epidemiology, Mailman School of Public Health, Columbia University, New York, \\ NY \\ 2Department of Medicine, College of Physicians and Surgeons, Columbia University, New York, \\ NY \\ ${ }^{3}$ Herbert Irving Comprehensive Cancer Center, Columbia University Medical Center, New York, \\ NY \\ ${ }^{4}$ Department of Biostatistics, Mailman School of Public Health, Columbia University, New York, \\ NY
}

\section{Abstract}

Purpose-U.S. cancer survivors commonly use vitamins/minerals and complementary and alternative medicine (CAM). We compare use of vitamins/minerals and CAM by adult cancer survivors and cancer-free adults, and estimate annual out-of-pocket expenses.

\begin{abstract}
Methods-Data on self-reported vitamin/mineral and CAM use in the past 12 months from the cross-sectional 2012 U.S. National Health Interview Survey were used to estimate prevalence of use and out-of-pocket expenditures. The cohort included adults with $(n=2,977)$ and without $(\mathrm{n}=30,551)$ a self-reported cancer diagnosis.
\end{abstract}

Results-Approximately $79 \%$ of cancer survivors and $68 \%$ of cancer-free adults reported using $\geq 1$ vitamins/minerals and/or CAM modality in the past year. Compared to cancer-free adults, cancer survivors were more likely to report use of vitamin/minerals ( $75 \%$ vs. $61 \%, \mathrm{P}<0.001$ ), herbal/non-vitamin supplements ( $24 \%$ vs. $19 \%, \mathrm{P}<0.001$ ), manipulative and body-based therapies ( $19 \%$ vs. $17 \%, \mathrm{P}=0.03$ ), and alternative medical systems ( $5 \%$ vs. $4 \%, \mathrm{P}=0.04$ ). Adult cancer survivors and cancer-free adults spent an annual estimated $\$ 6.7$ billion and $\$ 52$ billion out-ofpocket, respectively, on vitamins/minerals and CAM. Survivors spent $60 \%$ of the total on vitamins/minerals ( $\$ 4$ billion), 18\% ( $\$ 1.2$ billion) on herbal/non-vitamin supplements, and 7\% ( $\$ 0.5$ billion) on massage.

Conclusions-Compared with cancer-free adults, a higher proportion of cancer survivors report vitamin/mineral and CAM use. Cancer survivors, who accounted for $6.9 \%$ of the total population,

Corresponding author: Heather Greenlee, ND, PhD, 733 W $168^{\text {th }}$ Street, room 733, New York, NY 10032, Phone: 212-342-4130; Fax: 212-305-9413, hg2120@cumc.columbia.edu.

Conflicts of interest: None

Disclosures: An earlier version of this analysis was presented at the 2014 International Research Congress on Integrative Medicine and Health in Miami, Florida. 
accrued more than $11.4 \%$ of the annual out-of-pocket costs on vitamins/minerals and CAM spent by U.S. adults.

Implications for Cancer Survivors-Given the high use of vitamins/minerals and CAM in cancer survivors, studies are needed to analyze health outcomes and the cost:benefit ratio of such use.

\section{Keywords}

vitamins; complementary therapies; complementary medicine; healthcare costs; cancer

\section{Introduction}

Data from the 2007 National Health Interview Survey estimated that $38 \%$ of U.S. adults used complementary and alternative medicine (CAM) at a total out-of-pocket cost of $\$ 33.9$ billion, approximately $1.5 \%$ of total U.S. healthcare expenses [1]. Estimates from the same dataset showed that over $65 \%$ of adult cancer survivors had ever used at least one form of CAM and $43 \%$ used CAM in the previous 12 months, identifying cancer survivors as one of the largest U.S. patient populations using CAM [2]. A systematic review of vitamin and mineral supplement use among adult cancer survivors between 1999 and 2006 showed that $64-81 \%$ of survivors reported use, which is higher than the general US population [3]. More recent estimates of vitamin/mineral and CAM use among US adults with and without cancer, and the cost of such use, has not been described.

CAM modalities include vitamins and minerals, natural products, mind-body modalities, body-based therapies, and energy therapies [4]. Some therapies require practitioner visits while others involve purchasing over-the-counter products or supplies. Despite a limited evidence base for many modalities, cancer survivors use CAM for a variety of reasons, including preventing and treating side effects of standard cancer treatments, improving cancer survival, preventing and managing comorbid conditions, promoting general health and wellness, and addressing issues poorly managed by standard medical care [5]. Studies suggest that survivors with specific cancer diagnoses use different amounts and types of CAM [6, 7]. Of cancer survivors, breast cancer survivors are the most likely to use CAM, specifically dietary supplements [6].

We used nationally representative data from the 2012 National Health Interview Survey (NHIS) to describe the use of vitamins/minerals and CAM by U.S. adults with and without cancer and to estimate total annual out-of-pocket expenses. We examined specific characteristics associated with use and with spending. We hypothesized that vitamins/ minerals and CAM use would be high among cancer survivors, that use and spending patterns would differ by cancer type, and that use would be higher among cancer survivors than adults without a history of cancer. 


\section{Methods}

\section{Data}

Analyses used data from the cross-sectional 2012 NHIS, a nationally representative sample of non-institutionalized U.S civilians. The NHIS is an interviewer-administered questionnaire conducted annually by the Centers for Disease Control (CDC). Beginning in 2002, and every 5 years thereafter, the NHIS included an Alternative Medicine questionnaire for adults. In 2007, the NHIS added questions on CAM cost. Details on the NHIS survey design and the development of the Adult Alternative Medicine questionnaire have previously been reported [8].

\section{Study Population}

Analyses included adults who self-reported ever having received any cancer diagnosis, excluding participants with solely non-melanoma skin cancer ("cancer survivors"), and adults without a history of cancer diagnosis ("cancer-free adults"). See Figure 1 for CONSORT diagram. Cancer survivors were categorized by cancer type: breast, prostate, melanoma, female genital system (including cervical, endometrial, uterine, and ovarian), colorectal, urinary (including bladder and kidney), hematologic malignancies (including blood cancers and leukemia), lung, non-colorectal gastrointestinal (including gallbladder, pancreas, liver, esophageal, and stomach), and other cancers (including lymphoma, thyroid, throat-pharynx, bone, testicular, mouth/tongue/lip, brain, soft tissue, larynx-windpipe, and other). Participants with a history of more than one type of cancer were included in multiple categories.

\section{CAM use}

The Adult Alternative Medicine questionnaire asked about use of CAM in the past 12 months. In 2012, the questionnaire included vitamins/minerals in addition to 17 categories of CAM modalities: non-vitamin/mineral natural products; massage; chiropractic or osteopathic manipulation; yoga, tai chi, and qi gong; acupuncture; movement and exercise techniques; energy healing therapy; naturopathy; mind-body therapy; homeopathy; craniosacral therapy; Ayurveda; traditional healers; special diets; hypnosis; biofeedback; and chelation. The 17 categories were collapsed into broader categories, including biologically based therapies, manipulative and body-based therapies, mind-body therapies, alternative medical systems, energy healing therapy, and special diets, as previously done [1]. Chelation was not included in the analyses because so few cancer survivors reported chelation use in the past 12 months $(n=3)$. A participant was considered to be a user of a specific modality if they self-reported use, visited a practitioner, or attended a class in the past 12 months. To ascertain frequency of CAM use, depending on the type of modality, questions asked about the exact or approximate number of times the respondent visited a CAM practitioner, attended CAM classes, or purchased CAM supplies. Respondents were further categorized as non-users during the past 12 months, those who used vitamins and minerals only during the past 12 months ("vitamin/mineral user"), and those who used at least one CAM modality with or without vitamins and minerals in the past 12 months ("CAM +/- vitamin/mineral user"). The respondents were also asked to state their reasons for using CAM. Respondents were first asked to identify up to three of their most frequently used CAM modalities. Then, 
for each CAM modality, respondents were asked (yes/no) if they used the CAM modality for five different wellness-related reasons and 87 specific health condition-related reasons.

\section{Out-of-pocket costs}

The NHIS used a variety of methods to ascertain out-of-pocket CAM costs using a combination of cost per unit and frequency used, depending on the modality. Out-of-pocket spending calculations were based upon Nahin et al's prior publication describing national CAM spending [1]. For each modality, the NHIS first asked participants about insurance coverage for visiting a practitioner or attending a class. If insurance did not cover all associated costs, users were asked to report their exact or approximate out-of-pocket spending on the modality in the past 12 months for one practitioner visit or class. If insurance covered all associated costs, the out-of-pocket costs were treated as $\$ 0$ in analysis. When approximate costs were provided, annual spending was calculated using cost of visits/ classes multiplied by frequency of visits/classes. The NHIS used a variety of methods to assess out-of-pocket spending on self-help materials. Out-of-pocket costs for self-help materials were assessed if a participant visited a practitioner or attended a class in the past 12 months for chiropractic and osteopathic manipulation, massage, acupuncture, energy healing therapy, naturopathy, Ayurveda, craniosacral therapy, and traditional healers. For homeopathy, out-of-pocket costs for self-help materials were assessed if a participant reported use of homeopathy in the past 12 months that did not involve visiting a practitioner. For all other modalities, out-of-pocket costs for self-help materials were assessed regardless of whether a participant visited a practitioner or attended a class. For vitamins and minerals, the NHIS asked users for the exact or approximate cost of their most recent purchase of vitamins and minerals, in addition to their frequency of purchases; the NHIS included multivitamins and multiminerals in the aforementioned cost [9]. Cost of visiting a practitioner was not assessed for vitamins and minerals. For non-vitamin/mineral natural products, NHIS used the same methods as for vitamins and minerals to ascertain cost and also asked about the costs associated with visiting a practitioner. Out-of-pocket costs per practitioner visit and for purchasing homeopathic medicine, relaxation technique materials, and yoga, tai chi, and qigong classes were limited to either a specific response between $\$ 0$ to $\$ 499$, or a response of "\$500 or more", which was treated as $\$ 500$ in analysis. Similarly, the costs for purchasing self-help materials were limited between $\$ 0$ to $\$ 200$.

Next, the NHIS ascertained frequency of use. Possible NHIS responses for the frequency of CAM purchases, classes or visits to providers in the past 12 months included the following intervals: 2-5 times, 6-10 times, 11-15 times, and 16-20 times. Calculations used the midpoint of these intervals (i.e., 3.5 for 2-5 times), as previously used [1]. Responses of "only 1 time" or "more than 20 times" were considered to be 1 and 20 times, respectively. Based on prior cognitive testing results of the Complementary and Alternative Medicine Supplement of the 2007 NHIS [10], very few respondents reported purchase of supplements on a daily basis. Therefore responses of more than 365 times purchases per year were presumed errors, and were excluded from the analysis.

Analyses made use of both exact and approximate out-of-pocket cost data. For each participant, the costs of practitioner visits/classes, self-help materials, and dietary 
supplements were summed for each modality. The total CAM cost for each participant was calculated by summing an individual's reported out-of-pocket costs for each modality. If a participant reported use of a modality in the past 12 months, but had missing cost data, the assumption was made that they had no out-of-pocket spending in order to not overinflate spending estimates. Participants with unknown CAM use information were excluded from the cost estimate analysis.

\section{Comorbidity index}

A 9-item comorbidity index was created based upon the Department of Health and Human Services list of multiple chronic conditions [11]. The index sums each participant's number of self-reported comorbidities from the following list: hypertension two or more times in the past 12 months, asthma attack in the past 12 months, weak or failing kidneys in the past 12 months, chronic obstructive pulmonary disease, diabetes, hepatitis, coronary heart disease, stroke, and arthritis. Cancer was excluded from the index for the purpose of this analysis.

\section{Statistical analysis}

The NHIS achieves a representative population sample using a complex multistage area probability design [12]. All estimates were weighted by the adult record weights provided by NHIS in order to extrapolate estimates representative of the U.S. civilian noninstitutionalized adult population [9]. R statistical software (https://cran.r-project.org/) "survey" packages $[13,14]$ were used for all analyses.

Demographic and clinical characteristics of CAM users versus non-users were compared using the chi square test of independence. Descriptive analyses estimated total and perperson out-of-pocket CAM costs and number of practitioner visits for each modality among cancer survivors in the U.S, mean and median out-of-pocket costs by cancer type, time since diagnosis, number of cancers, as well as mean and median cost by population characteristics. The uses of each CAM modality were also compared between cancer survivors and cancer-free adults using chi-squared test. Estimates with a relative standard error of more than $30 \%$ do not meet the standard of reliability or precision, and therefore were not shown. Instead, these estimates were marked by an asterisk (*). The relative standard error was calculated as: relative standard error $=(\mathrm{SE} / \mathrm{Est}) * 100$, where $\mathrm{SE}$ is the standard error, and Est is the point estimate. In addition, estimates for groups with a sample size less than 50 were not displayed.

\section{RESULTS}

Of the 34,525 adults sampled in the 2012 NHIS, 2,977 were cancer survivors and 30,551 were cancer-free adults (Table 1). Among cancer survivors, 36.4\% used at least one CAM modality other than vitamins and minerals in the past 12 months ("CAM user"), $38.9 \%$ used only vitamins and minerals in the past 12 months ("vitamin/mineral user"), and $27.4 \%$ reported no CAM use in the past 12 months ("non-users"). Cancer-free adults reported slightly less use with $33.1 \%$ reporting CAM use, $32.5 \%$ reporting vitamin/mineral use, and $31.8 \%$ reported no use. Among cancer survivors and cancer-free adults, similar proportions 
reported using four or more types of CAM in the past 12 months (9.0\% and 9.2\%, respectively).

\section{Demographic and clinical characteristics}

In both cancer-free adults and cancer survivors, compared to non-users, vitamin/mineral and CAM users were more likely to be older, female, non-Hispanic white, have a higher education, married, have a higher income, have insurance, and have a personal health care provider (Table 1). In both populations, compared to non-users, vitamin/mineral and CAM users were more likely to perceive their health status as good, very good, or excellent. However, vitamin/mineral and CAM users were more likely to have more comorbid conditions, especially among those who only reported use of vitamin/minerals. Among cancer survivors, compared to non-users, vitamin/mineral and CAM users were slightly more likely to be survivors of breast, melanoma, and colorectal cancers, although cancer type was unknown for about $25 \%$ of survivors (Table 1).

\section{Annual CAM use}

Over three quarters (78.8\%) of cancer survivors used vitamins/minerals or at least one CAM modality in the past 12 months, as compared to $67.5 \%$ in adults without a history of cancer (Table 2). The majority of cancer survivors used vitamins and minerals (74.8\%), while the least commonly used therapies included craniosacral therapy and Ayurveda ( $0.2 \%$ each). Yoga, tai chi, and qi gong had the highest per-person mean (22.3) practitioner visits/classes in the past 12 months, followed by relaxation techniques (median=10, mean=21.4) and movement and exercise techniques (median=10.0, mean=17.3). Compared to cancer-free adults, cancer survivors were more likely to report use of vitamin/minerals (74.8\% vs. $61.4 \%, \mathrm{P}<0.001)$ and herbal and non-vitamin supplements $(23.7 \%$ vs. $18.5 \%, \mathrm{P}<0.001)$. In addition, cancer survivors were more likely to report use of manipulative and body-based therapies ( $18.6 \%$ vs. $16.6 \%, \mathrm{P}=0.03)$ and alternative medical systems $(5.4 \%$ vs. $4.4 \%$, $\mathrm{P}=0.04)$, though the clinical significance of these is small as differences of only $1-2 \%$ were observed.

\section{Annual out-of-pocket CAM spending}

On average, cancer survivors spent $\$ 445$ annually on combined costs for all modalities (median $\$ 75 /$ year, range $\$ 0-\$ 52,980$ ). They spent the majority of costs on vitamins and minerals (median $=\$ 40 /$ year, mean $=\$ 280 /$ year). Acupuncture and non-vitamin $/$ mineral natural products had the second and third highest annual median costs, $\$ 172$ and $\$ 75$, respectively (Table 2). In contrast, cancer-free adults on average spent slightly less $\$ 368$ annually on all CAM modalities, but had a similar median and range (median \$72/year, range $\$ 0-\$ 55,067)$.

Cancer survivors in the U.S. spent an estimated $\$ 6.7$ billion in annual out-of-pocket vitamin/ mineral and CAM costs, accounting for approximately $11.4 \%$ of the $\$ 58.5$ billion annual out-of-pocket vitamin/mineral and CAM costs for all U.S adults (Table 3). Total expenses included a combination of practitioner visits, classes, and self-help materials. Among cancer survivors, vitamins and minerals accounted for the largest portion of the total cost with over $\$ 3.9$ billion spent annually; non-vitamin/mineral natural products accounted for $\$ 1.2$ billion, 
massage and chiropractic/osteopathic manipulation each accounted for $\$ 0.5$ billion. Among cancer-free adults, the out-of-pocket cost for vitamin/minerals and CAM was estimated to be $\$ 51.8$ billion, of which $\$ 29.2$ billion was spent on vitamin/minerals, $\$ 9.7$ billion on nonvitamin/mineral natural products, and $\$ 76.5$ million on massage.

\section{CAM spending by cancer type}

Each cancer group spent the majority of their total out-of-pocket expenditures on vitamins and minerals, with the exception of urinary cancer survivors who spent the majority of their costs on non-vitamin/mineral natural products (data not shown). Breast cancer survivors had the highest annual median per-person CAM costs $(\$ 84)$, followed by prostate cancer $(\$ 60)$ and other female genital system cancer (\$60) (Table 4).

As a group, breast cancer survivors accrued the highest out-of-pocket vitamin/mineral and CAM costs ( $\$ 1.1$ billion), followed by prostate cancer ( $\$ 0.6$ billion), and female genital system cancer ( $\$ 0.6$ billion) (data not shown). Non-colorectal gastrointestinal cancer survivors had the lowest out-of-pocket CAM costs ( $\$ 55.4$ million).

\section{CAM spending by population characteristics}

Online Supplemental Table 1 shows median and mean amounts spent on vitamins/minerals and CAM by demographic and clinical characteristics. Compared to cancer-free adults, cancer survivors who report higher median spending were younger, did not have health insurance, and perceived their health to be excellent.

\section{CAM spending by years since diagnosis and number of cancers}

Online Supplemental Table 2 shows estimated median CAM costs by years since diagnosis and number of cancers. Groups where annual median spending exceeded \$100/year include cancer survivors using non-vitamin/mineral natural products who were either within one year of diagnosis or 6-10 years post diagnosis). Cancer survivors with a history of one cancer diagnosis spent twice as much on vitamins/minerals as compared to those with 2 or more cancer diagnoses.

\section{Reasons for CAM use}

Online Supplemental Table 3 reports the wellness and health condition-related reasons for $\mathrm{CAM}$ and vitamin/mineral use among cancer survivors and cancer-free adults. Cancer survivors and cancer-free adults reported similar proportions of wellness-related reasons for CAM use, including general wellness or general disease prevention $(66.5 \%$ and $64.4 \%$, respectively), improving energy (33.0\% and 39.8\%, respectively, and improving immune function (30.8\% and $29.7 \%$, respectively). Similarly, the top four reported health conditionrelated reasons for CAM use were the same for cancer survivors and cancer-free adults: back pain or problem (14.4\% vs. $14.7 \%$, respectively), joint pain/stiffness (9.8\% vs. $6.6 \%$, respectively), cardiovascular condition (9.5\% vs. $5.5 \%$, respectively), and neck pain (6.6\% vs. $7.0 \%$, respectively). Only $3.9 \%$ of cancer survivors reported using CAM specifically to treat their cancer. 


\section{DISCUSSION}

In 2012, approximately $79 \%$ of U.S. adult cancer survivors and $68 \%$ of cancer-free adults used vitamins/minerals and/or at least one form of CAM, spending a total of $\$ 6.7$ billion and $\$ 51.8$ billion out-of-pocket on CAM use, respectively. In the 2012 NHIS, cancer survivors comprised estimated $6.9 \%$ of the U.S. noninstitutional adult population (14.8 million), but spent $11.4 \%$ of the out-of-pocket CAM costs. Given the $\$ 125$ billion estimated total U.S. healthcare costs associated with cancer in 2010, out-of-pocket costs of $\$ 6.7$ billion on vitamins/minerals and CAM represent a substantial proportion of overall cancer costs [15].

Over the past decade, estimates of total out-of-pocket CAM costs in the U.S. among all adults ranged from $\$ 9$ to $\$ 34$ billion, with the large range due to differences in sampling methods and CAM definitions [16, 1]. Using the 2007 NHIS, Nahin et al. estimated that $38.3 \%$ of U.S. adults used CAM and spent $\$ 33.9$ billion out-of-pocket [1]. The 2007 analysis excluded vitamins/minerals despite the fact that previous studies have shown that use of vitamin and mineral supplements in cancer populations is high, ranging from 44-84\% [17-20]. Because of this high use, we were interested in out-of-pocket spending on vitamins and minerals in this population. Therefore, our estimates were higher than those reported by Nahin et al. [1], with an estimated annual out-of-pocket of $\$ 59$ billion in 2012. The definition of CAM has evolved over time and varies in the literature [6], with some definitions including [21-24] and excluding [25, 5] vitamins and minerals. For example, the National Center for Complementary and Integrative Health (NCCIH) includes vitamins and minerals in their definition of CAM [8], but not all prior NHIS CAM analyses have included vitamins and minerals in the definition [5]. In order to facilitate comparisons of use between different types of CAM-related health promotion strategies, future studies may need to consistently include vitamins and minerals in the definition of CAM.

Vitamin/mineral and CAM use is common among U.S. cancer survivors. Our study estimates $79 \%$ of cancer survivors used vitamins/minerals or at least one form of CAM in a 12-month time period; the large majority of CAM users used dietary supplements, including multivitamins/minerals, vitamins and minerals (75\%), as well as herbal supplements (24\%). In comparison, fewer cancer-free adults (68\%) used vitamins/minerals or at least one form of CAM in a 12-month time period. These findings are consistent with the literature on cancer survivors who participate the NHIS [5]. In 2007, Mao et al found $43 \%$ of cancer survivors reported CAM use in the previous 12 months, with a definition excluding multivitamins/minerals, vitamins and minerals. Evidence-based clinical guidelines exist on the use of integrative therapies during and after cancer treatment, but there are few highlevel recommendations due to limited data as evidenced in recently published clinical guidelines [26-28]. In the oncology setting, there is a growing body of literature suggesting that mind-body interventions are effective for improving treatment related side effects, quality of life, psychological conditions. However, in contrast, few dietary supplement interventions have proven to be effective at changing clinical endpoints and some dietary supplements have proven to be harmful. The high prevalence of dietary supplement use among cancer survivors have led to safety concerns in light of the limited data on the effects of such use [29]. 
Previous studies showed that cancer survivors primarily use CAM for general disease prevention, immune enhancement, and pain symptoms, rather than as a treatment for cancer $[30,2]$. In this study, we also examined CAM use as treatments for medical conditions. We found cancer survivors and cancer-free adults used CAM for similar reasons and in similar amounts. Less than $4 \%$ cancer survivors used CAM as a treatment for cancer. These results, along with findings by Mao et al. and Lafferty et al., suggest that the elevated CAM cost in cancer survivors may be driven by treatment for pain symptoms and other chronic conditions $[5,30]$.

Recently, patients' out-of-pocket costs were described as a toxicity of cancer treatment, and it is now suggested that physicians discuss out-of-pocket treatment costs with their patients, especially treatments with little or poorly understood benefits [31]. Newly diagnosed cancer survivors spent an average $\$ 1,107$ to $\$ 1,711$ out-of-pocket for medical services and supplies in the first year following diagnosis, with average annual costs thereafter ranging from $\$ 747$ to $\$ 1,451$ [32]. These costs include costs associated with ambulatory care, inpatient care, and prescription medications, but do not include costs associated with vitamins/minerals and CAM use. We found that on average, cancer survivors spent $\$ 445$ per year out-of-pocket on CAM, the majority of which was spent on dietary supplements. This is not an insignificant amount given the already substantial costs associated with living with cancer and the high probability of patients being on disability or unemployed during treatment and recovery. In order to make financial decisions, it would be useful for cancer survivors to able to evaluate the cost:benefit ratio of using any specific form CAM. However, such data are limited.

To date, very few studies have examined CAM costs among cancer survivors. In one study of brain tumor patients, CAM users spent an average $\$ 69$ per month on CAM use, with approximately one fifth of patients spending an average $\$ 100$ or more per month [33]. A study of early stage breast cancer patients showed that these women spent an average \$32 out-of-pocket on alternative medical systems in the four weeks immediately following surgery [34]. These early studies suggest that CAM costs may vary by cancer type, period of use, and may be driven by unique issues associated with each particular type of cancer. In our analyses, we identified differences in CAM use and spending between cancer groups. We found that melanoma survivors used more modalities than other cancer types, and had the highest per-person CAM costs, and urinary (including bladder and kidney) survivors were the only cancer group to spend more on non-vitamin/mineral natural products than on vitamins and minerals.

The major strength of this analysis is the use of the population-based NHIS dataset, which contains detailed self-reported information on use and out-of-pocket spending on several types of CAM modalities. There is currently no other data-source providing this type of information. Additionally, the self-reported data allows for an understanding of the most important types of CAM for participants, as well as reasons for CAM use. NHIS sampling methods allow for one of the most accurate health estimates of minority persons in the U.S.

The 2012 NHIS dataset does have specific limitations related to the analyses of out-ofpocket costs associated with CAM use. One limitation of the 2012 NHIS dataset was the inability to separate out the costs associated with multivitamins/multiminerals from the costs 
associated with individual vitamins and minerals. Therefore, we included multivitamins and multiminerals with singular vitamins and minerals. In 2007, Nahin et al. reported that nonvitamin/mineral natural products accounted for $44 \%$ of the total CAM spending among U.S. adults. Excluding vitamin and mineral costs in our analyses, non-vitamin/mineral natural products contributed $48 \%$ of the total CAM costs among cancer survivors. These findings suggest that cancer survivors are using non-vitamin/mineral natural products at least as frequently as the general adult population. Another limitation of the 2012 NHIS dataset was that for any individual it only ascertains reasons for use of the three most frequently used forms of CAM. Therefore, if a participant used more than three forms of CAM the reasons for such use were not captured. Additionally, it is not possible to accurately estimate the specific costs of using CAM for cancer, or any other disease specific condition, because it is only possible to estimate the costs for the top three reasons stated. Given that $9 \%$ of cancer survivors reported using four or more forms of CAM, any estimate of CAM use specifically for cancer would likely be an underestimation because it would not capture the costs beyond the top three modalities identified by a participant. Finally, the NHIS did not differentiate primary and secondary cancer, making it impossible to differentiate the costs in survivors with multiple cancers and survivors experiencing metastases.

In addition, several methodological limitations may also impact the accuracy of the estimated CAM use and spending in cancer survivors. As the NHIS only interviews noninstitutionalized persons, we expect that a healthy participant bias may underestimate the total number of cancer survivors. The National Cancer Institute (NCI) estimated 13.7 million cancer survivors in the U.S. as of January 2012. The NHIS's estimated 20 million cancer survivors in 2012 is likely higher because NCI's estimate did not include non-invasive cancers [35]. As NHIS does not collect detailed data on whether the cancer was a primary or secondary cancer, cancer stage or treatment received, we were unable to examine the association between severity of cancer/treatment and CAM use and spending. The CAM cost data is an imprecise measure due to self-report, as well as the calculations based on approximated number of visits and costs, which may be subject to misclassification. The one-time collection of the cost data may not be extrapolated to represent cost over 12 months. It is important to note that cost data is often skewed to the right, meaning there are a minority of participants with high out-of-pocket spending and that median spending is relatively low (\$75) in comparison to mean spending (\$445). Alternative methods to calculate the mean of right-skewed data were proposed by Briggs and Gray, who suggested a non-parametric approach of bootstrapping would be more appropriate [36]. However, this method has not incorporated the complex survey design. Therefore, we estimated both the mean and median out-of-pockets, and considered the median to be more representative of the central tendency of the costs. Although the data are skewed, the total cost in the population is unlikely to be biased. The right skewness of the data was largely driven by the presence of many zero costs for most modalities. These zero costs came from participant who only reported use but not any cost, or from participant reported that their costs were fully covered by insurance. In addition, the estimated cost is likely to be underestimated as the cost per practitioner visit was limited to $\$ 500$ or below, and cost for purchasing selflearning materials was limited to $\$ 200$ or below. However, the majority of participants reported costs within this range, with less than $10 \%$ of participants reported spending more 
than these limits across all CAM modalities, except for acupuncture (26.7\% users spent more than $\$ 200$ on learning materials) and Ayurveda (16.7\% users spent more than $\$ 200$ on learning materials) (data not shown). Sensitivity analyses by excluding participants with truncated cost generated similar albeit slightly lower out-of-pocket CAM costs (analyses not shown). The cross-sectional nature of these analyses precludes examination of the temporal relationship between use of vitamins/minerals and CAM and a cancer diagnosis. Despite these limitations, this study represents the most robust estimate to date of out-of-pocket CAM costs for cancer survivors in the U.S.

In summary, 79\% of cancer survivors and 68\% of cancer-free adults used CAM in 2012. It is important that clinicians are aware of the extent to which cancer survivors are using CAM, and are aware that the majority of this use is not for cancer specific concerns, but rather for general wellness, pain and cardiovascular reasons. This information can inform patientprovider conversations about the rationale for any CAM use. Cancer survivors accounted for only $6.9 \%$ of the total population but spent more than $11.4 \%$ of the annual out-of-pocket costs on CAM. It is important that patients, as well as clinicians, are aware of the financial implications of the use of vitamin/mineral and CAM modalities. Studies need to examine health outcomes associated with vitamin/mineral and CAM use among cancer patients, and to assess cost effectiveness of such use in this population.

\section{Supplementary Material}

Refer to Web version on PubMed Central for supplementary material.

\section{Acknowledgments}

The authors thank Richard Nahin, PhD at the National Center for Complementary and Integrative Health for his insightful comments and helpful suggestions on the data analysis and interpretation. Funding was provided by National Cancer Institute K23CA141052 (to Heather Greenlee).

\section{REFERENCES}

1. Nahin RL, Barnes PM, Stussman BJ, Bloom B. Costs of complementary and alternative medicine (CAM) and frequency of visits to CAM practitioners: United States, 2007. Natl Health Stat Report. 2009; (18):1-14. [PubMed: 19771719]

2. Mao JJ, Palmer CS, Healy KE, Desai K, Amsterdam J. Complementary and alternative medicine use among cancer survivors: a population-based study. J Cancer Surviv. 2011; 5(1):8-17. [PubMed: 20924711]

3. Velicer CM, Ulrich CM. Vitamin and mineral supplement use among US adults after cancer diagnosis: a systematic review. J Clin Oncol. 2008; 26(4):665-673. [PubMed: 18235127]

4. National Center for Complementary and Integrative Health. [Accessed 6 Dec 2015] Get the facts: Cancer and Complementary Health Approaches. https:/nccih.nih.gov/sites/nccam.nih.gov/files/ Get_The_Facts_Cancer_and_CHA_07-15-2014.pdf

5. Mao JJ, Farrar JT, Xie SX, Bowman MA, Armstrong K. Use of complementary and alternative medicine and prayer among a national sample of cancer survivors compared to other populations without cancer. Complement Ther Med. 2007; 15(1):21-29. [PubMed: 17352968]

6. Patterson RE, Neuhouser ML, Hedderson MM, Schwartz SM, Standish LJ, Bowen DJ, et al. Types of alternative medicine used by patients with breast, colon, or prostate cancer: predictors, motives, and costs. J Altern Complement Med. 2002; 8(4):477-485. [PubMed: 12230908] 
7. Greenlee H, White E, Patterson RE, Kristal AR. Supplement use among cancer survivors in the Vitamins and Lifestyle (VITAL) study cohort. J Altern Complement Med. 2004; 10(4):660-666. [PubMed: 15353022]

8. Stussman BJ, Bethell CD, Gray C, Nahin RL. Development of the adult and child complementary medicine questionnaires fielded on the National Health Interview Survey. BMC Complement Altern Med. 2013; 13:328. [PubMed: 24267412]

9. Centers for Disease Control and Prevention. [Accessed 6 Dec 2015] About the National Health Interview Survey. 2012. http://www.cdc.gov/nchs/nhis/about_nhis.htm

10. Willson S, Stussman B, Maitland A, Nahin RL. Role of self-concept in answering survey questions on complementary and alternative medicine: challenges to and strategies for improving data quality. J Altern Complement Med. 2009; 15(12):1319-1325. [PubMed: 19954343]

11. Goodman RA, Posner SF, Huang ES, Parekh AK, Koh HK. Defining and measuring chronic conditions: imperatives for research, policy, program, and practice. Prev Chronic Dis. 2013; 10:E66. [PubMed: 23618546]

12. Adams PFKW, Martinez ME. Summary health statistics for the U.S. population: National Health Interview Survey, 2012. National Center for Health Statistics. Vital Health Stat. 2013; 10(259)

13. Lumley T. Analysis of complex survey samples. J Stat Softw. 2004; 9(1):1-19.

14. Therneau TM, Lumley T. R, Survival analysis: [computer program]. CRAN. 2014

15. Mariotto AB, Yabroff KR, Shao Y, Feuer EJ, Brown ML. Projections of the cost of cancer care in the United States: 2010-2020. J Natl Cancer Inst. 2011; 103(2):117-128. [PubMed: 21228314]

16. Davis MA, Martin BI, Coulter ID, Weeks WB. US spending on complementary and alternative medicine during 2002-08 plateaued, suggesting role in reformed health system. Health Aff (Millwood). 2013; 32(1):45-52. [PubMed: 23297270]

17. Greenlee H, Kwan ML, Ergas IJ, Strizich G, Roh JM, Wilson AT, et al. Changes in vitamin and mineral supplement use after breast cancer diagnosis in the pathways study: a prospective cohort study. BMC Cancer. 2014; 14(1):382. [PubMed: 24884705]

18. Link AR, Gammon MD, Jacobson JS, Abrahamson P, Bradshaw PT, Terry MB, et al. Use of SelfCare and Practitioner-Based Forms of Complementary and Alternative Medicine before and after a Diagnosis of Breast Cancer. Evid Based Complement Alternat Med. 2013; 2013:16.

19. Greenlee H, Kwan ML, Ergas IJ, Sherman KJ, Krathwohl SE, Bonnell C, et al. Complementary and alternative therapy use before and after breast cancer diagnosis: the Pathways Study. Breast Cancer Res Treat. 2009; 117(3):653-665. [PubMed: 19184414]

20. Miller MF, Bellizzi KM, Sufian M, Ambs AH, Goldstein MS, Ballard-Barbash R. Dietary Supplement Use in Individuals Living with Cancer and Other Chronic Conditions: A PopulationBased Study. J Am Diet Assoc. 2008; 108(3):483-494. [PubMed: 18313431]

21. Eisenberg DM, Davis RB, Ettner SL, et al. Trends in alternative medicine use in the united states, 1990-1997: Results of a follow-up national survey. JAMA. 1998; 280(18):1569-1575. [PubMed: 9820257]

22. Eisenberg DM, Kessler RC, Foster C, Norlock FE, Calkins DR, Delbanco TL. Unconventional Medicine in the United States -- Prevalence, Costs, and Patterns of Use. N Engl J Med. 1993; 328(4):246-252. [PubMed: 8418405]

23. Sohl SJ, Weaver KE, Birdee G, Kent EE, Danhauer SC, Hamilton AS. Characteristics associated with the use of complementary health approaches among long-term cancer survivors. Support Care Cancer. 2014; 22(4):927-936. [PubMed: 24263621]

24. National Center for Complementary and Alternative Medicine. [Accessed 6 Dec 2015] Complementary, Alternative, or Integrative Health: What's In a Name?. National Center for Complementary and Alternative Medicine, Bethesda, Maryland. 2013. http://nccam.nih.gov/ health/whatiscam

25. Barnes PM, Bloom B, Nahin RL. Complementary and alternative medicine use among adults and children: United States, 2007. Natl Health Stat Report. 2008; 10(12):1-23. [PubMed: 25585443]

26. Deng GE, Frenkel M, Cohen L, Cassileth BR, Abrams DI, Capodice JL, et al. Evidence-based clinical practice guidelines for integrative oncology: complementary therapies and botanicals. J Soc Integr Oncol. 2009; 7(3):85-120. [PubMed: 19706235] 
27. Deng GE, Rausch SM, Jones LW, Gulati A, Kumar NB, Greenlee H, et al. Complementary therapies and integrative medicine in lung cancer: Diagnosis and management of lung cancer, 3rd ed: American College of Chest Physicians evidence-based clinical practice guidelines. Chest. 2013; 143(5 Suppl):e420S-e436S. [PubMed: 23649450]

28. Greenlee H, Balneaves LG, Carlson LE, Cohen M. Clinical Practice Guidelines on the Use of Integrative Therapies as Supportive Care in Patients Treated for Breast Cancer. J Natl Cancer Inst Monogr. 2014; 2014(50):346-358. [PubMed: 25749602]

29. Luc L, Baumgart C, Weiss E, Georger L, Ambrosone CB, Zirpoli G, et al. Dietary supplement use among participants of a databank and biorepository at a comprehensive cancer centre. Public Health Nutr. 2015; 18(5):916-926. [PubMed: 24866812]

30. Lafferty WE, Tyree PT, Devlin SM, Andersen MR, Diehr PK. Complementary and alternative medicine provider use and expenditures by cancer treatment phase. Am J Manag Care. 2008; 14(5):326-334. [PubMed: 18471036]

31. Ubel PA, Abernethy AP, Zafar SY. Full disclosure--out-of-pocket costs as side effects. N Engl J Med. 2013; 369(16):1484-1486. [PubMed: 24131175]

32. Guy GP Jr, Ekwueme DU, Yabroff KR, Dowling EC, Li C, Rodriguez JL, et al. Economic burden of cancer survivorship among adults in the United States. J Clin Oncol. 2013; 31(30):3749-3757. [PubMed: 24043731]

33. Armstrong T, Cohen MZ, Hess KR, Manning R, Lee EL, Tamayo G, et al. Complementary and alternative medicine use and quality of life in patients with primary brain tumors. J Pain Symptom Manage. 2006; 32(2):148-154. [PubMed: 16877182]

34. Wyatt G, Sikorskii A, Wills CE, Su H. Complementary and alternative medicine use, spending, and quality of life in early stage breast cancer. Nurs Res. 2010; 59(1):58-66. [PubMed: 20010046]

35. Howlader, NAMN.; Krapcho, M.; Garshell, J.; Miller, D.; Altekruse, SF., et al. [Accessed 6 Dec 2015] SEER Cancer Statistics Review, 1975-2011. National Cancer Institute, Bethesda, MD. 2014. http://seer.cancer.gov/archive/csr/1975_2011/

36. Briggs A, Gray A. The distribution of health care costs and their statistical analysis for economic evaluation. J Health Serv Res Policy. 1998; 3(4):233-245. [PubMed: 10187204] 


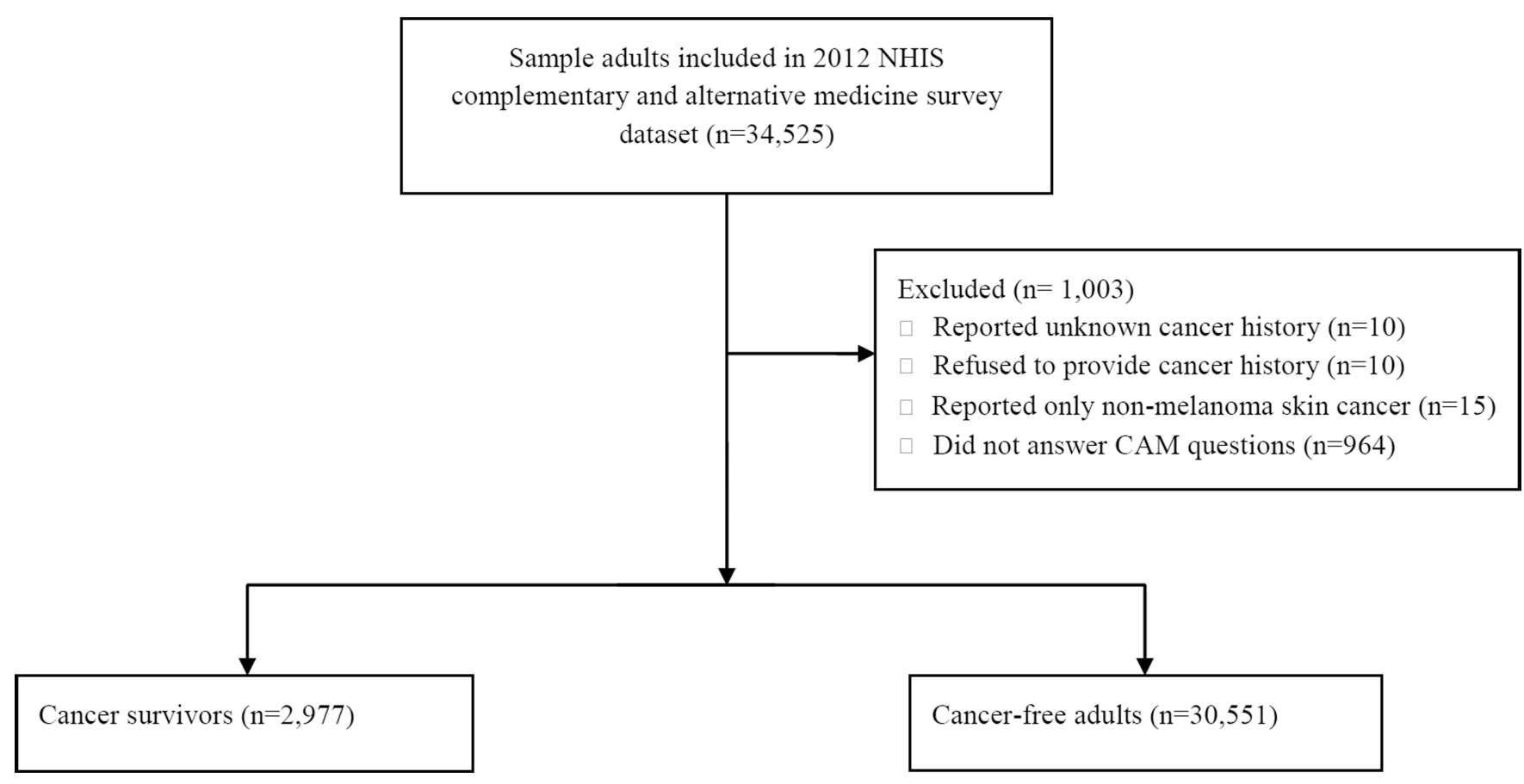

Figure 1.

Sample selection of 2012 NHIS adult participants with data on cancer history and complementary and alternative medicine use. 


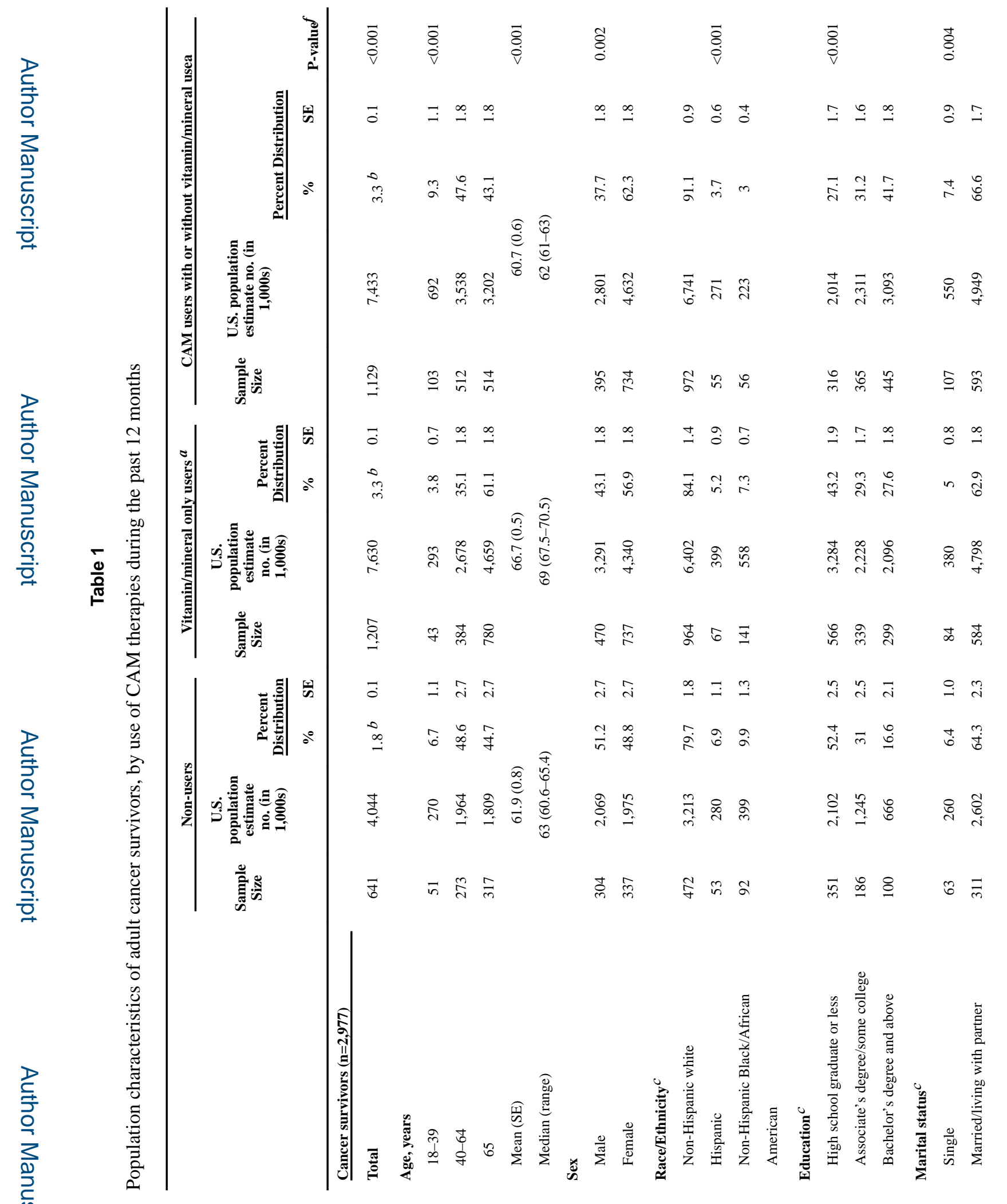




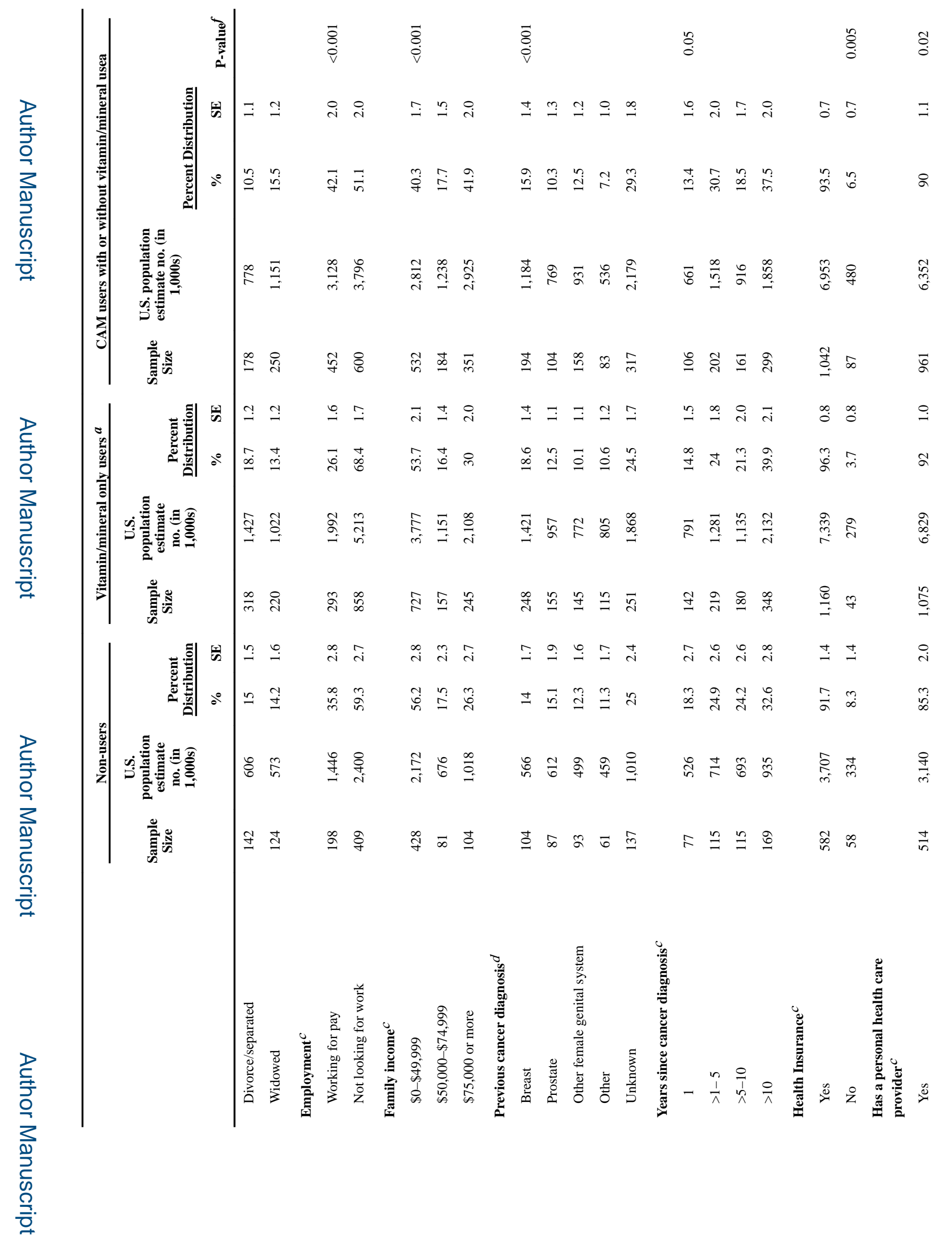

J Cancer Surviv. Author manuscript; available in PMC 2017 October 01. 


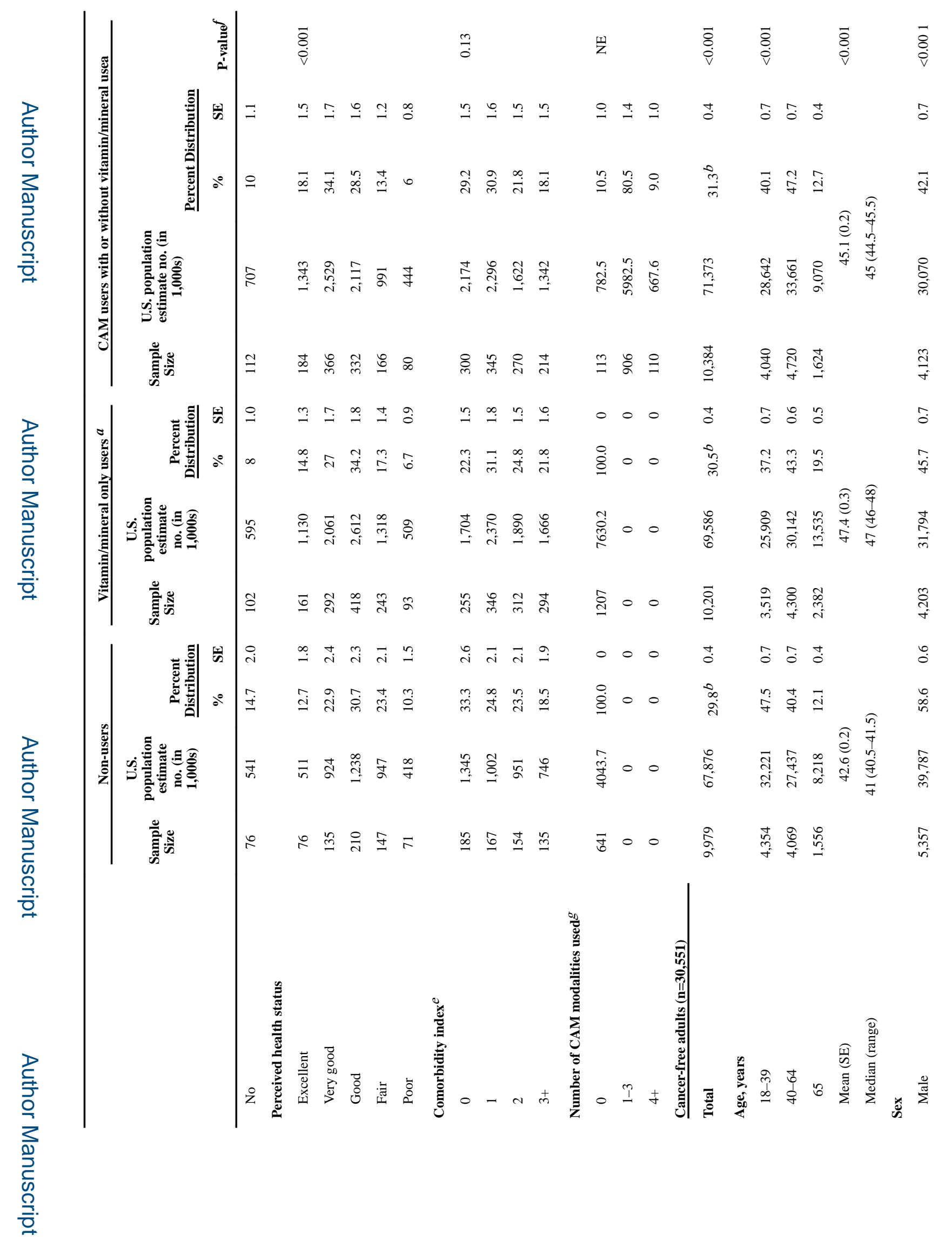

J Cancer Surviv. Author manuscript; available in PMC 2017 October 01. 


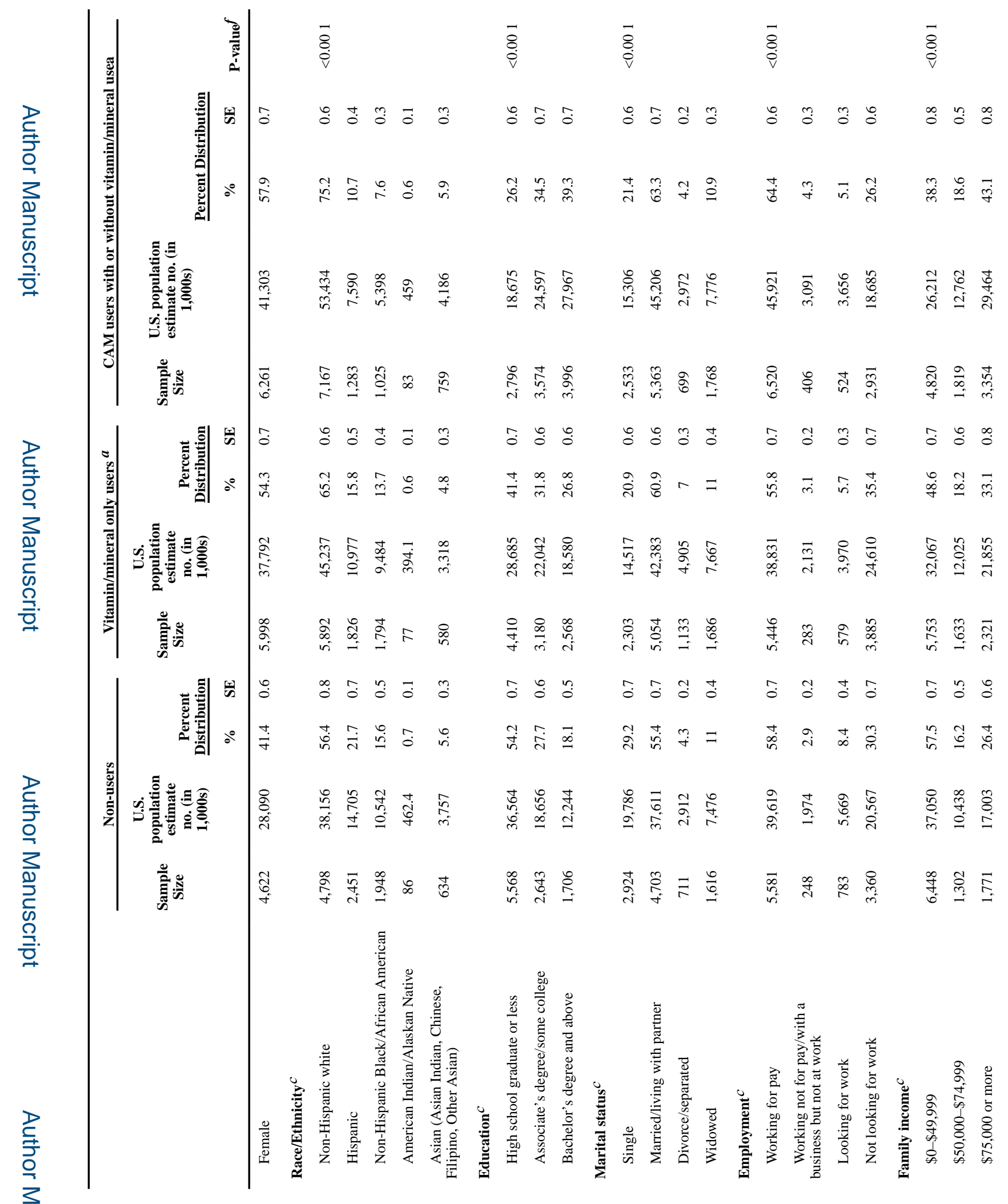




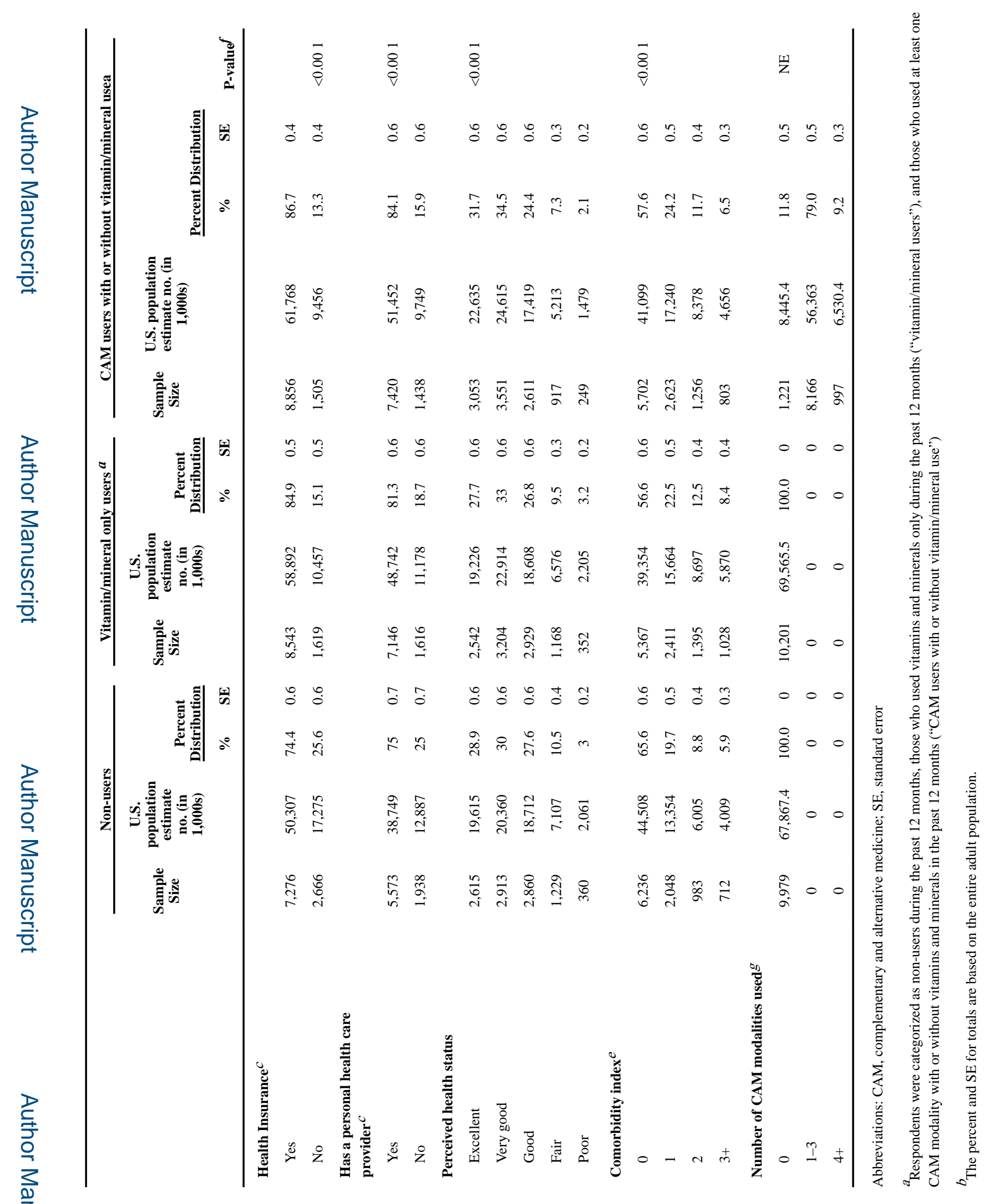




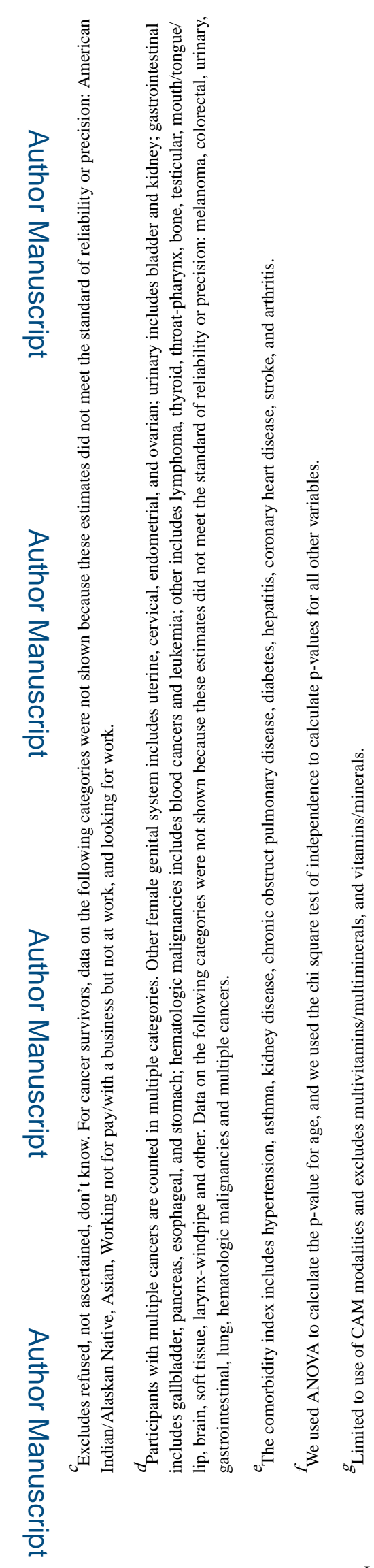

J Cancer Surviv. Author manuscript; available in PMC 2017 October 01. 


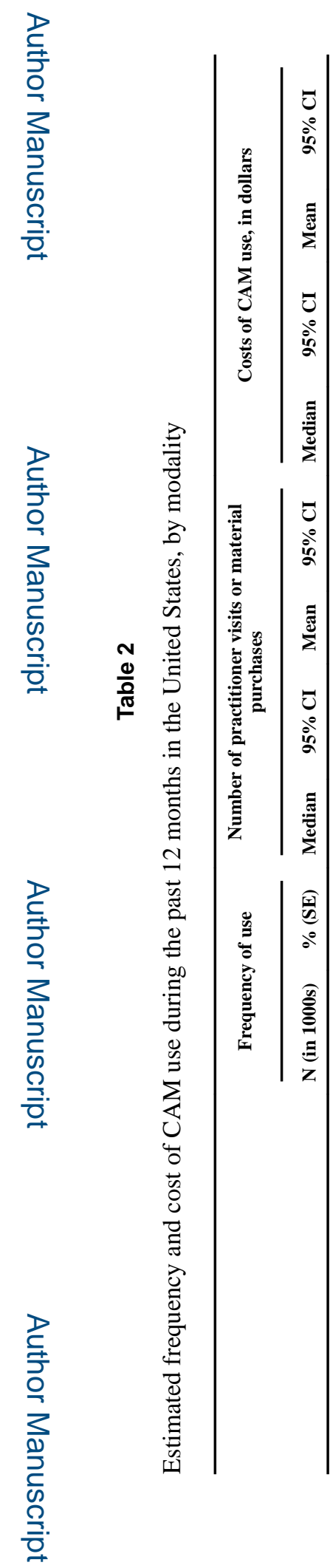

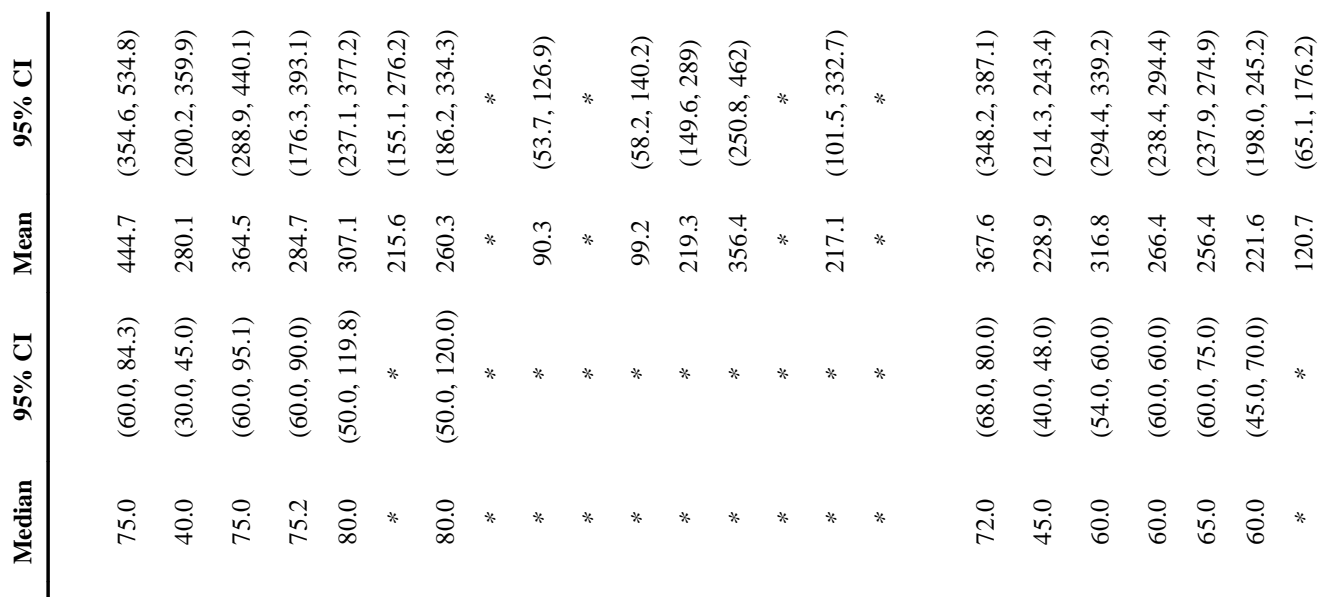

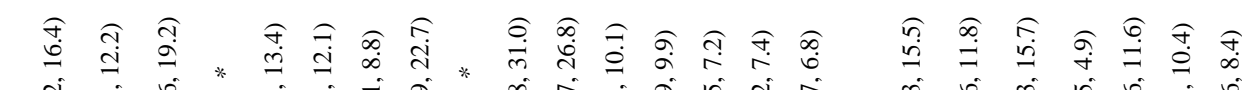

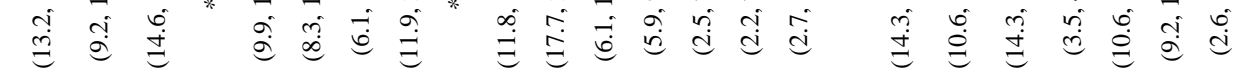

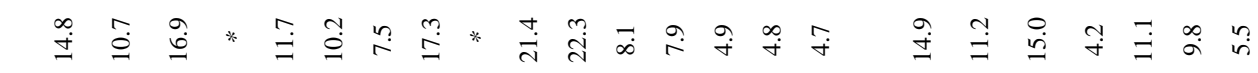

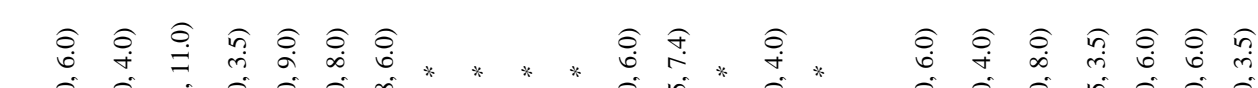

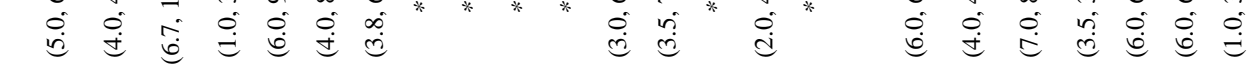

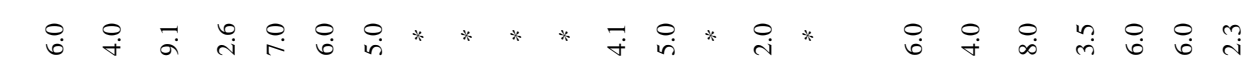

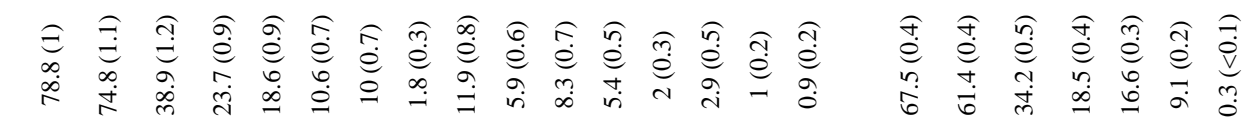

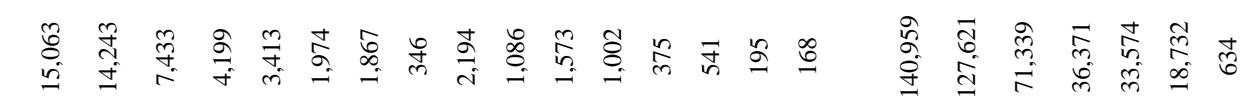

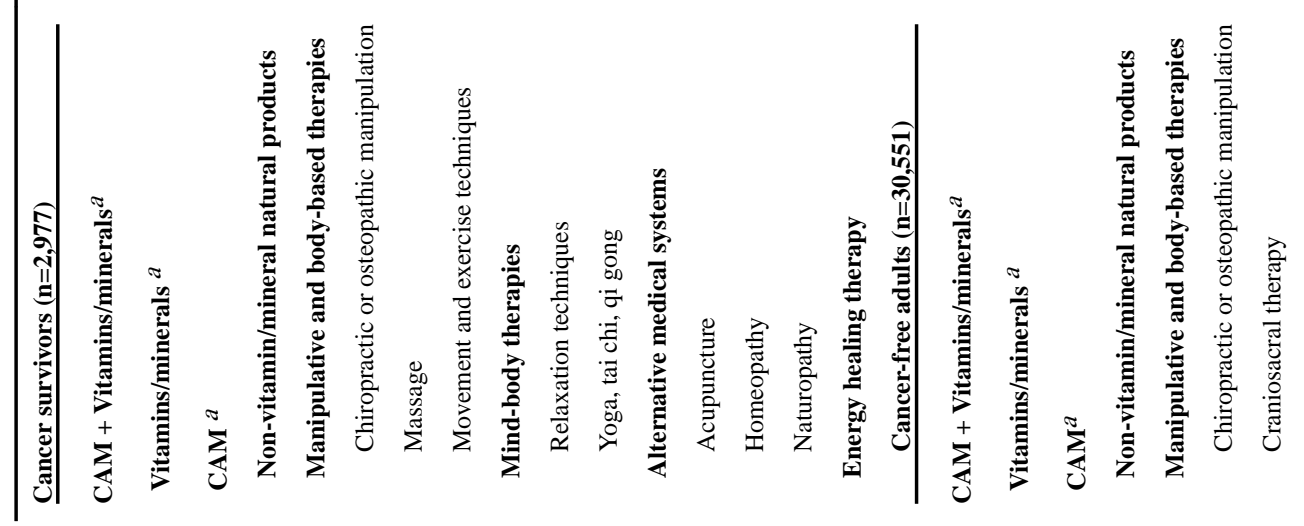

J Cancer Surviv. Author manuscript; available in PMC 2017 October 01. 


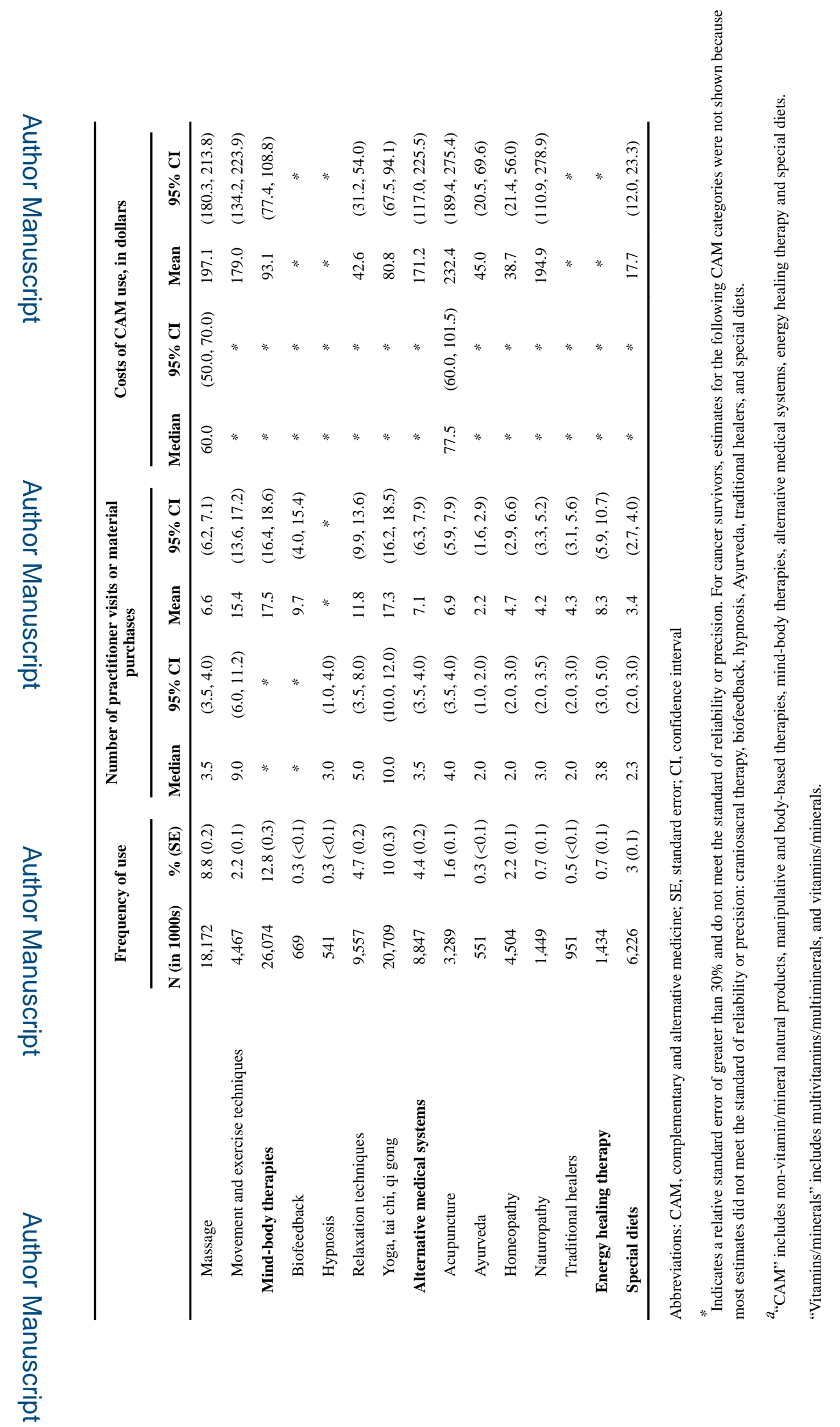

J Cancer Surviv. Author manuscript; available in PMC 2017 October 01. 


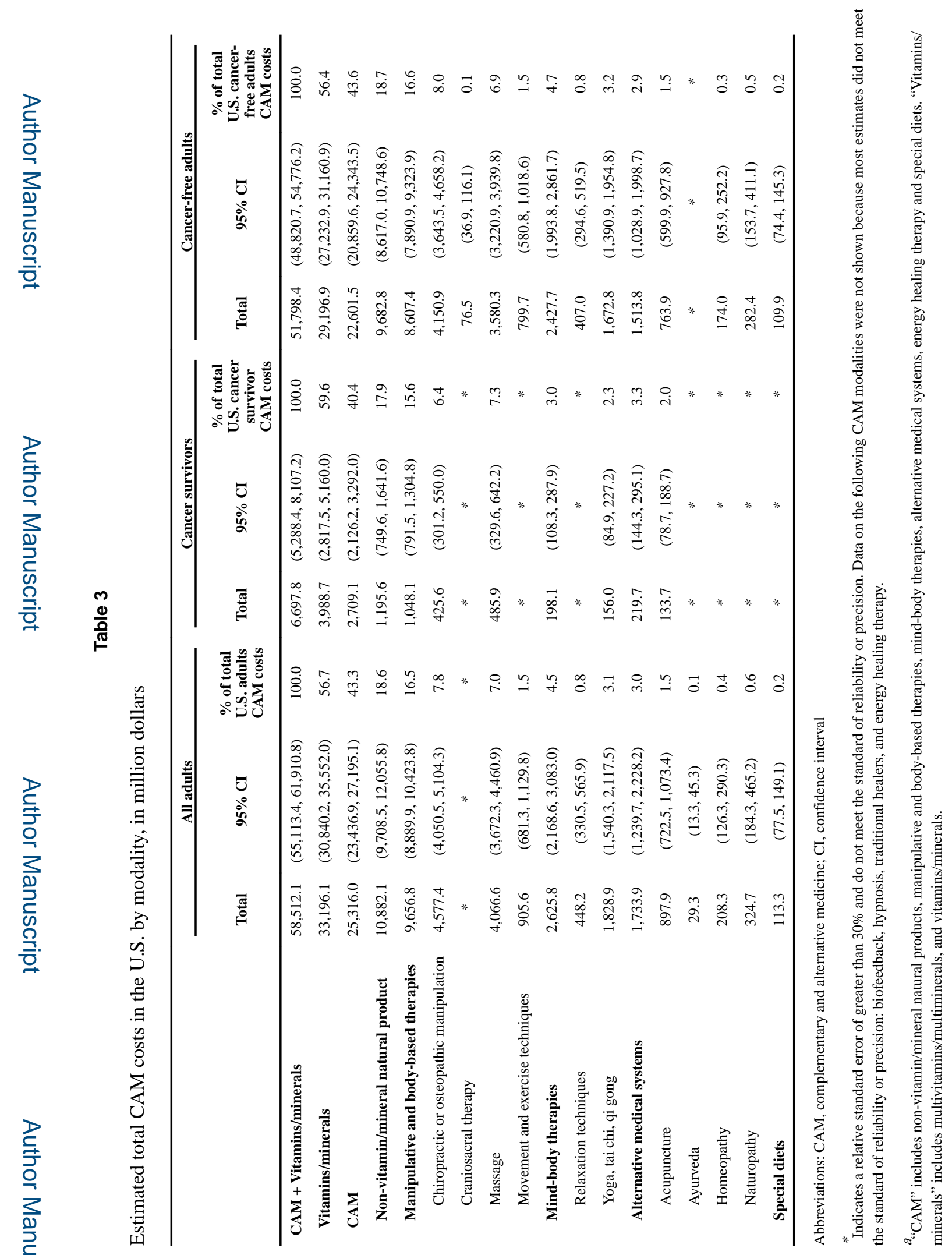

J Cancer Surviv. Author manuscript; available in PMC 2017 October 01. 


\section{Table 4}

CAM use and estimated median CAM costs (in dollars) by modality and cancer type in the past 12 months ${ }^{a}$

\begin{tabular}{|c|c|c|c|}
\hline & Breast & Prostate & Other female genital system \\
\hline \multicolumn{4}{|l|}{ Use of CAM, \% (SE) } \\
\hline CAM + Vitamins/minerals ${ }^{b}$ & $82.1(2.1)$ & $73.8(3.1)$ & $77.3(2.8)$ \\
\hline Vitamins/minerals $b$ & $79.6(2.2)$ & $71.9(3.1)$ & $70.6(3.1)$ \\
\hline $\mathbf{C A M}^{b}$ & $37.3(2.7)$ & $32.9(3.5)$ & $42.3(3.3)$ \\
\hline Non-vitamin/mineral natural product & $17.2(2.0)$ & $23.9(3.2)$ & $20.9(2.8)$ \\
\hline Manipulative and body-based therapies & $18.6(2.2)$ & $18.9(3.2)$ & $23.5(2.7)$ \\
\hline Mind-body therapies & $14.4(2.1)$ & $6.7(2.2)$ & $16.5(2.5)$ \\
\hline \multicolumn{4}{|c|}{ Median cost in dollars by modality, dollars (95\% CI) } \\
\hline CAM + Vitamins/minerals ${ }^{b}$ & $84.0(61.3,106.7)$ & $60.0(27.5,92.5)$ & $60.0(28.0,92.0)$ \\
\hline Vitamins/minerals $b$ & $120.0(84.2,155.8)$ & $100.0(54.1,145.9)$ & $120.0(77.6,162.4)$ \\
\hline $\mathbf{C A M}^{b}$ & $84.0(61.3,106.7)$ & $60.0(27.5,92.5)$ & $60.0(28.0,92.0)$ \\
\hline Non-vitamin/mineral natural product & $120.0(84.2,155.8)$ & $*$ & $*$ \\
\hline Manipulative and body-based therapies & $80.0(41.3,118.7)$ & * & * \\
\hline Mind-body therapies & $*$ & * & * \\
\hline \multicolumn{4}{|c|}{$\begin{array}{l}\text { * Indicates a relative standard error of greater than } 30 \% \text { and do not meet the standard of reliability or precision. Data on the following CAM } \\
\text { modalities were not shown because most estimates did not meet the standard of reliability or precision: alternative medical systems and special } \\
\text { diets. }\end{array}$} \\
\hline \multicolumn{4}{|c|}{${ }^{a}$ Categories are not mutually exclusive, therefore individuals with multiple cancers are included in multiple categories. } \\
\hline \multicolumn{4}{|c|}{ 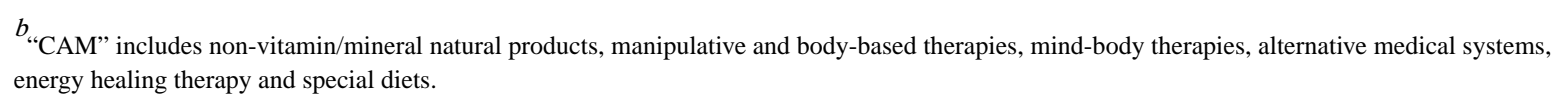 } \\
\hline
\end{tabular}

